\title{
Histogensis of the Pars Nervosa in Buffalo
}

\author{
H. F. Attia \\ Histology cytology dept. Faculty of veterinary medicine. Benha University \\ hossam222@yahoo.comE-mail:
}

With 20 figures

Received 8 March 2008 , Accepted April 2008

\begin{abstract}
This study was carried out on 50 embryos and fetuses and 40 pars nervosa of the post natal buffalos at various ages to clear out the development of the pars nervosa. The primordial of the pars nervosa was appeared at $15 \mathrm{~mm}$ CVRL, as evagination from the brain behind the optic chiasma.

It increased in size and surrounded by the pars intermedia of the adenohypophysis. The pituicytes appeared at $60 \mathrm{~mm}$ CVRL, and increased in size and characterized by large ovoid centrally located nuclei and eosinophilic cytoplasm with cytoplasmic process that extended to made synapse with the nerve fibers. The nerve fiber of the hypothalamic hypophyseal tract was appeared at $120 \mathrm{~mm}$ CVRL as fine nerve fibers extended in the pars nervosa and between the pituicytes.

Neurosecretory dilatation was appeared at 180 $\mathrm{mm} \mathrm{CVRL} \mathrm{as,} \mathrm{dark} \mathrm{basophilic} \mathrm{ovoid} \mathrm{to} \mathrm{circular} \mathrm{bod-}$ ies between the pituicytes with numerous basophilic granules were appeared in the contour of the herring bodies. The numbers of the herring bodies were decreased with the age advance especially in the post natal life.
\end{abstract}

\section{Key Words}

Pars nervosa, Buffalo, Histogenesis.

\section{Introduction}

The hypophysis develops from two components, one from the ectodermal roof of the stomodeum while the other is specialized extension from the brain wall. The hypophysis consists of two parts, anterior (adenohypophysis) and posterior (neurohypophysis). (Arey, 1965).

The premordium of the neurohypophysis is seen behind the optic chiasma as evagination of the diencephalons at $12 \mathrm{~mm}$ CVRL in goat embryo. The pituicytes differentiates at $19 \mathrm{~mm}$ CVRL, the neurosecretory materials seen at $25 \mathrm{mmCVRL}$ and the nerve fibers or the hyopothamo-hypophyseal tract reach the neurohypophysis at 55mm CVRL (Singh\& Dhingra, 1982).

J. vet. anat.
At, 17 days of fetal life in rat embryo, a nalage of the neural lobe is formed as amass of cells which later on differentiate to pituicytes. The neurosecretory activity is detected at 18 days of fetal life with nerve fibers and blood capillaries (Galabov\& Schlebler, 1978).

The pars nervosa forms the most posterior part of the pituitary gland. It mainly consists of pituicytes, nerve fibers and neurosecretory granules ( Salama \&Deeb, 1975) in buffalo-cow and (Lawrence and Sarah ,1964) in Opossum and (Singh \& Dhingra, 1982 ) in sheep.

Different types of nervous termination were described in the human neurohypophysis, two types of axons were detected according to their dilatation and contents of neurosecretory granules. Type (A), characterized by numerous dilatation and $100-30 \mathrm{~nm}$ in size while type (B), exhibit simple swelling and 50$100 \mathrm{~nm}$ in size (Seyama, Pearl and Takei, 1980).

The neurosecretory material of the pars nervosa has an important influence on wide spectrum of physiological process as pregnancy and lactation. (Singh\& Dhingra, 1982). It released oxytocin and vasopressin hormones ( Yousuf, Pow and Mizuno, 1993 and Senda and Yu, 1999) in mouse.

The aim of the study is to throw more lights on the histogenesis of the buffalo's pars nervosa

\section{Material and methods}

The pituitary glands of 50 buffalo embryos and fetuses and 40 pars nervosa at different ages of postnatal life were collected. Their length ranging from $1.5 \mathrm{~cm}-90 \mathrm{~cm}$. The crown vertebral rump length of buffalo embryos and fetuses were measured and the age was determined according to the formula given by Abdel-Raouf and El-Nagar (1970).

$X=28.660+4.496 * C V R L$ for fetuses less than $20 \mathrm{~cm}$ $Y=73.544+2.256^{*}$ CVRL for fetuses more than $20 \mathrm{~cm}$

The postnatal ages were determined by dentation according to the calculation given by Miller and Robertson (1959). 
These specimens were examined for free of any disease and abnormalities. They collected from many abattoirs in Cairo, kalyobia and Giza Governorates. The embryos and fetuses were freed from their embryonic membranes just after

Department of Cytology and Histology, Faculty of Veterinary Medicine, Benha University, Egypt collection from the abattoirs. The embryos from Icm-6cmCVRL were taken as a whole to the fixatives. While the fetuses from $7 \mathrm{~cm}-99 \mathrm{cmCVRL}$ their heads were cut and opened and the pituitary glands were removed carefully and immediately immersed in the fixatives. Many fixatives were used, Susa, Bourn's and Neutral formalin fluids.

The specimens were dehydrated, cleared and embedded in paraffin. Saggital and cross sections were earned out on the pituitary glands.. The specimens were stained with general, special and histochemical stains. Harris hematoxylin , Crossmon's trichrome stain, Gomori reticulin method, Verhoeffs method, Periodic acid Schiff, Alcian blue method, Alcian blue/ PAS, Acid fuchsin aniline blue and Bromin-Alcian blue-OrangeG-Fuchsin( BR-ABOFG) method. These methods after Bancroft, Cook, Stirling and Turner (1994).

\section{Results}

The primordial of the pars nervosa was appeared at $15 \mathrm{~mm}$ CVRL, as evagination from the brain behind the optic chiasma. The bulk of the primordial was consisted of mesenchymal cells and surrounded by the cells of the anterior lobe. It extends as down growth close to the caudal wall of the Rathke's pouch. (Fig.1), the primordial of the pars nervosa was lined by multilayer of epithelial tissues that resembled the ependyme lining of the diocole. It increased in size and penetrate deeper along the fibers of the diaphragma sella which inward make depression along the contour of the sella turcica bone at 32mm CVRL (Fig.2).

Very fine reticular fibers were located in the parenchyma of the pars nervosa (Fig.3) at $45 \mathrm{~mm}$ CVRL. Small oval cells were appeared at $60 \mathrm{~mm}$ CVRL, which considered the pituicytes, the nervosa increased in size with the other parts of the pituitary gland. Few blood capillaries were appeared between the cells of the anterior lobe but not in the pars nervosa (Fig.4).

The numbers of the pituicytes were increased especially around the center of the pars nervosa at $120 \mathrm{~mm}$ CVRL, it was oval in shape with dense and dark staining affinity (Fig.5). The nerve fibers of the hypothalamic hypophyseal tract was appeared at $120 \mathrm{~mm}$ CVRL as fine nerve fibers extended in the pars nervosa and between the pituicytes
At $150-320 \mathrm{~mm}$ CVRL, the pituicytes were numerous and differentiated to pale and dark cells. Numerous blood capillaries extended from the pars intermedia to the pars nervosa (Fig.6). Short nerve fibers were extended in the parenchyma between the pituicytes and around the blood capillaries which were increased in number and widely distributed between the cells and fibers of the pars nervosa (Fig.7).

Neurosecretory dilatation was appeared at $180 \mathrm{~mm}$ CVRL as, dark basophilic ovoid to circular bodies between the pituicytes. Numerous basophilic granules were appeared in the contour of the herring bodies at $250 \mathrm{~mm}$ CVRL (Fig.8). The pituicytes were increased in size and characterized by large ovoid centrally located nuclei and eosinophilic cytoplasm with cytoplasmic process that extended to made synapse with the nerve fibers (Fig.9).

At $450-650 \mathrm{~mm}$ CVRL, both of the nerve fibers and the pituicytes were increased. The pituicytes were concentrated in the center of the pars nervosa (Fig.10). The cells were appeared as large ovoid nuclei that occupied most of the cell cytoplasm with long cytoplasmic process. The nerve tracts were increased and branched between the pars nervosa cells at $600 \mathrm{mmCVRL}$ (Fig.11).

At750-900mmCVRL, the nerve tracts were increased in number with numerous branching and anatomizing especially around the blood capillaries. The herring bodies were large ovoid in shape with shiny eosinophilic appearance and numerous large basophilic neurosecretory granules. (Fig.12). Fine reticular fibers were extended between the cells and nerve tract of the pars nervosa at $900 \mathrm{~mm}$ CVRL (Fig.13).

Both of the nerve tract and the connective tissue fibers were faint alcian blue reaction (Fig.14) and weak PAS positive reaction. While the pituicytes and the herring bodies were weak to moderate PAS positive reaction (Fig.15).

The pars nervosa at 1.5 month post natal was similar to that of the $900 \mathrm{~mm}$ CVRL, the nerve tracts were increased and branched, and less numerous pituicytes were located between the fibers than that of the prenatal periods. The herring bodies were increased in size and concentrated around the blood capillaries (Fig.16).

The pars nervosa of 2-5 year was characterized by numerous nerve tracts which were concentrated in the ventral part of the pars nervosa. numerous blood capillaries (Fig.17). The nerve tracts and the connective tissue fibers were also weak PAS positive reaction. The reticular fibers were concentrated between the nerve tracts as fine fibers and some collagen fibers were only appeared around the nerve tracts as

Vol 1 No1, (2008) 22 - 28 
connective tissue fibers of the nerve fibers (Fig.18) The herring bodies were appeared ovoid with large circumscribed basophilic neurosecretory granules. (Fig.19).

The pars nervosa of 11 years was characterized by numerous nerve tracts, but showed less anatomizing in comparison to the previous stage . the pituicytes were mainly concentrated in the ventral part of the pars nervosa with darkly stained basophilic nuclei and eosinophilic cytoplasmic process. The herring bodies were few with faint acidophilic reaction and some of them were devoid of the basophilic neurosecretory granules (Fig.20).

\section{Discussion}

The present work revealed that, the primordial of the pars nervosa was appeared at $15 \mathrm{~mm}$ CVRL, as evagination from the brain behind the optic chiasma. The bulk of the primordial was consisted of mesenchymal cells and surrounded by the cells of the anterior lobe. It was extended as down growth close to the caudal wall of the Rathke's pouch. These results were augmented by House (1943) in ox at $13.5 \mathrm{~mm}$ CVRL, while Shanklin (1944), at 10mm CVRL in pig and Singh and Dhingra, (1982) in goat at $16 \mathrm{~mm}$ CVRL.

The primordial of the pars nervosa was lined by multilayer of epithelial tissues that resembled the ependyme lining of the diocole. This epithelium later on will differentiate to be the pituicytes. Similar suggestion was discussed by House (1943) in ox, Shanklin (1944), in pig and Singh and Dhingra, (1982) in goat, Brahams, (1932) in cat and Falin, (1961) in man.

Small oval cells with dark stained oval nuclei were appeared at $60 \mathrm{~mm}$ CVRL, which considered the pituicytes. The numbers of the pituicytes were increased especially around the center of the pars nervosa at $120 \mathrm{~mm} \mathrm{CVRL}$, it was oval in shape with dense and dark staining affinity. These cells were suggested to form the pituiblasts which later on differentiated to pituicytes as mentioned in the fetal pig by Shanklin (1944).

These cells were characterized by darkly stained nucleus and lightly stained cytoplasm. The cytoplasm characterized by cytoplasmic process that extended through out the pars nervosa making synapse with the nerve tracts of the hypothalmo hypophyseal tract. This orientation was only recorded in ox (House, 1943) and (Badwi, Fath ElBab, Hassan, Nafady and Aziza Selim, 1985).

The nerve fibers were appeared at $120 \mathrm{~mm}$ CVRL which increased in number and then branched downward and make synapse with the cytoplasmic process of the pituicytes. It mainly concentrated around the blood capillaries. Similar findings were reported in the bull by (Badwi, Fath EIBab, Hassan, Nafady and Aziza Selim, 1985). The fibers or the hyopothamo-hypophyseal tract form terminal network and end glomeruli around the pituicytes and the blood vessels (Liss, 2005).

The nervosa increased in size with the other parts of the pituitary gland. Few blood capillaries were appeared between the cells of the anterior lobe but not in the pars nervosa. The blood capillaries penetrate the pars nervosa in late stage of prenatal life as that of the pars nervosa of the goat (Singh and Dhingra, 1982).

Our results revealed different shapes of pituicytes were randomly distributed throughout the bulk of the pars nervosa. It was characterized by darkly stained nucleus and shinny eosinophilic cytoplasm it was characterized by cytoplasmic processes that were extended between the nerve tracts. It mainly runs with the whole length of the nerve fibers. On the other hand (Heidelberg, 1970), reported in frog and mammals, two types of pituicytes were noticed in the pars nervosa of the frog (pale and dense), while third type was noticed in the mammals (intermediate), the types could classified according to their cytoplasmic densities.

The neurosecretory granules (Herring bodies) were appeared at $180-250 \mathrm{~mm}$ CVRL as ovoid structure in the contour of the nerve fibers. It was characterized by basophilic granules and shiny acidophilic cytoplasm, it increased in size and number by age advanced then decreased at the old age. The number of the herring bodies were decreased in the old age (Singh and Dhingra, 1982) in sheep, (Loesch,1981) and ( Rechardt and Hervonen, 1982 )in rat .

\section{References}

Abd El Raouf, M and El Nagar, M.A (1970): Further study of the biometry and development of the Egyptian buffalo foetus.J. Vet.Sci.UAR7(1):129140

Arey, L.B.(1965): Developmental Anatomy. A text book and laboratory manual of embryology $7^{\text {th }}$ ed.W.B.Saunders company .( Philadelphia and London) Toppan company , LTD (Tokyo Japan).

Badwi, H; Fath El-Bab, M.R ; Hassan,A.H.S; Nafady,A and Aziza,A.Selim(1985): Chronological development of the neurohypophysis in bull calves from birth to puberity. Egypt J. of Histo.1 (8)1985- Proc. ${ }^{\text {th }}$.Sci. Meet. Egypt.Soc.Histol.Cytol. 1984

Bancroft,J.D; Cook,H.C; Stirling,R.W and Turner,D.R (1994): Manual of Histological Techniques and their diagnostic applications, $2^{\text {nd }}$ ed. Churchill Livingstone, Edinburgh, London. 
Brahams.S(1932): The development of hypophysis in cat ( Felis domesticus). J.anat.50:261-281.

Falin,L.I(1961): the development of human hypophysis and differentiation of cells of its anterior lobe during embryonic life .Acta Anat.44: :188-205.

Galabov,P\& Schlebler,T.H (1978): The ultrastructure of the developing neural lobe . Cell Tissue Research.189:313-329.

Heidelberg,S.B (1970): Electron microscopic observations on synapse like contacts between pituicytes and different types of nerve fibers in the anuran parsnervosa. Cell and Tissue Research. Vol.110.No.1.27-39.

House.E.L(1943): the development of hypophysis in the ox. Am.J.Anat.73:1-25.

Lawrence M.Roth and Sarah A. Luse (1964): Fine structure of the neurohypophysis of the Opossum (Didelphis virginiana).

J.Cell.Biology.Vol.20.No.3. 459-472.

Leopold Liss (2005): Nervous end structures in the human neurohypophysis. Journal of the neural transmission. Vol.17.no.3-4.p.294-300.

Loesch, A (1981): The neurosecretory axons in the neurohypophysis of the rat : an electron microscopic study. J. Ultrastru. Res. 77(3):344353.

Miller, W.C and Robertson, E.D.S (1959): practical animal husbandry . Oliver\&Boyed, London.

Rechardt, L and Hervonen, H (1982): Ultrastructural changes in the neurohypophysis of the aged male rat. Cell Tissue Res. 226(1):51-62.

Salama , A \&Deeb, S (1975): The pituitary gland of buffalo cow : Ahistomorphological study . J. Egypt. Vet. Med. Assoc.35 (2):5-14.

Senda, T and Yu,W (1999): Kinesin cross bridges between neurosecretory granules and microtubules in the mouse neurohypophysis) J Neurosci Lett (262(1): 69-71

Seyama, S. Pearl, G.S and Takei, Y ( 1980): Ultrastructural study of the human neurohypophysis. I. Neurosecretory axons and their dilatations in the pars nervosa. Cell Tissue Research. 205, (2) :253-271

Shanklin.W.M(1944): Histogensis of the pig neurohypophysis. Am.J.Anat.74:327-353.

Yousuf, S A, Pow, D V and Mizuno, N( 1993): Ultra structural demonstration of exocytosis of neurosevretory granules in the neurohypo physis of the frog Rana temporalia. J Neu rosci Lett. 159(12):32-40

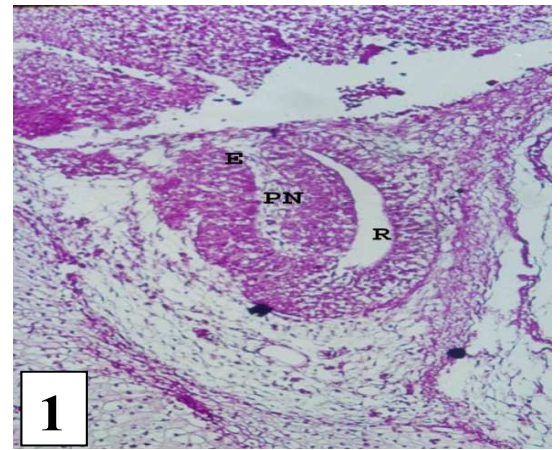

Fig.1: Sagittal section in the pituitary gland of the buffalo fetus at $15 \mathrm{~mm}$ CVRL; showing the primordial of the pars nervosa (PN), Rathke's pouch ( $R$ ), pars nervosa epithelium (E ). H\&E.X10

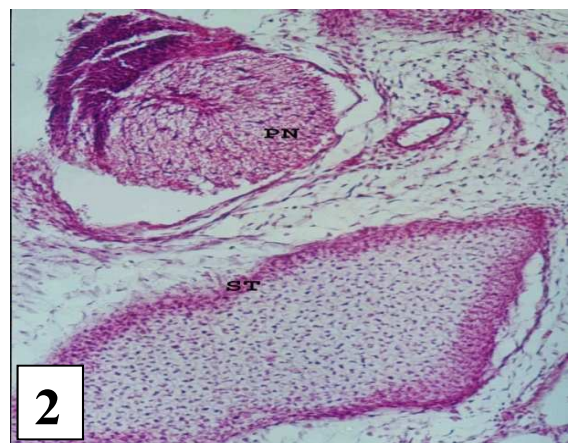

Fig.2: Sagittal section in the pituitary gland of the buffalo fetus at $32 \mathrm{~mm}$ CVRL; the pars nervosa (PN), diaphragma sella (DS) and sella turcica (ST).

H\&E X10

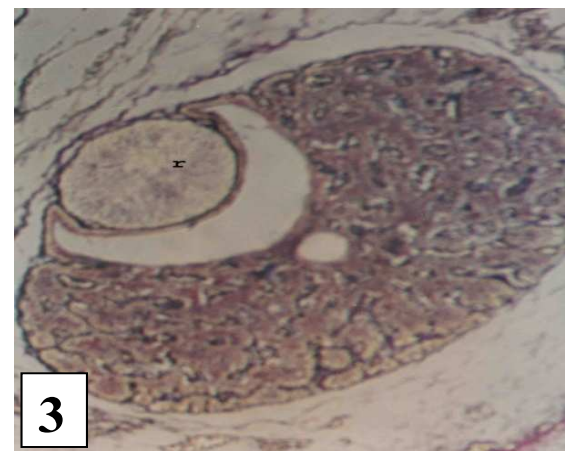

Fig.3: Sagittal section in the pituitary gland of the buffalo fetus at $45 \mathrm{~mm}$ CVRL; the pars nervosa fine reticular fibers (r).Gomori reticulin.X10 

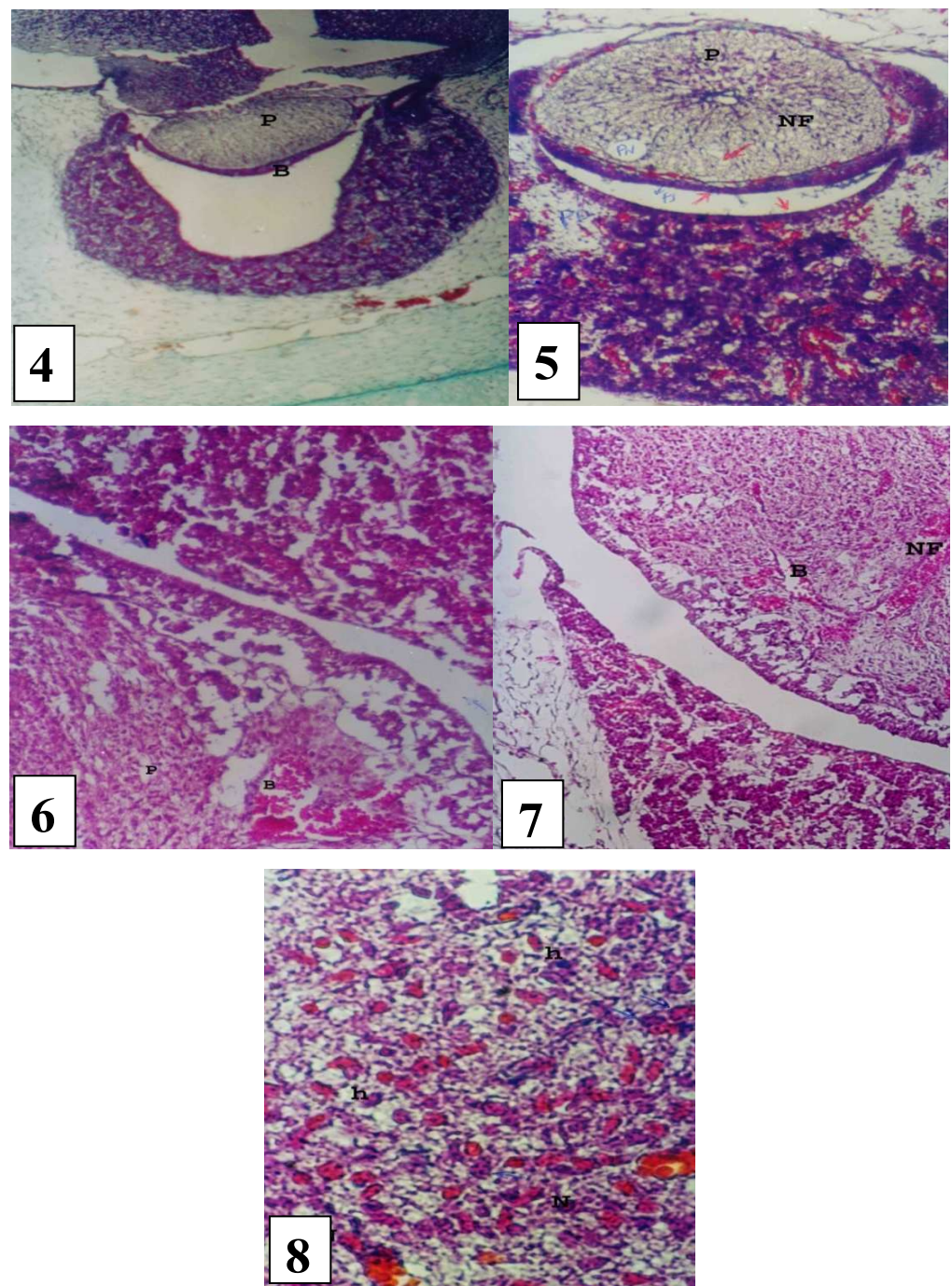

Fig.4: Sagittal section in the pituitary gland of the buffalo fetus at $60 \mathrm{~mm}$ CVRL; the primordial of the pituicytes $(P)$ and the blood capillaries at the pars intermedia and pars distalis (B). Crossman's.X40

Fig.5: Sagittal section in the pituitary gland of the buffalo fetus at $120 \mathrm{~mm}$ CVRL; showing; the first appearance of the nerve fibers (NF) and the developing pituicytes (P). BR-AB-OFG X40

Fig.6: Sagittal section in the pituitary gland of the buffalo fetus at $240 \mathrm{~mm}$ CVRL; showing; the blood capillaries (B) and pituicytes (p). BR-AB-OFG .X40

Fig.7: Sagittal section in the pituitary gland of the buffalo fetus at $220 \mathrm{~mm}$ CVRL; showing; the increased number of nerve fibers (NF) and the blood capillaries (B). BR-AB-OFG X10

Fig.8: Sagittal section in the pituitary gland of the buffalo fetus at $180 \mathrm{~mm} \mathrm{CVRL;} \mathrm{showing;} \mathrm{the} \mathrm{herring} \mathrm{bodies}$ (h) and the neurosecretory materials (N). BR-AB-OFG X40

J. vet. anat. 

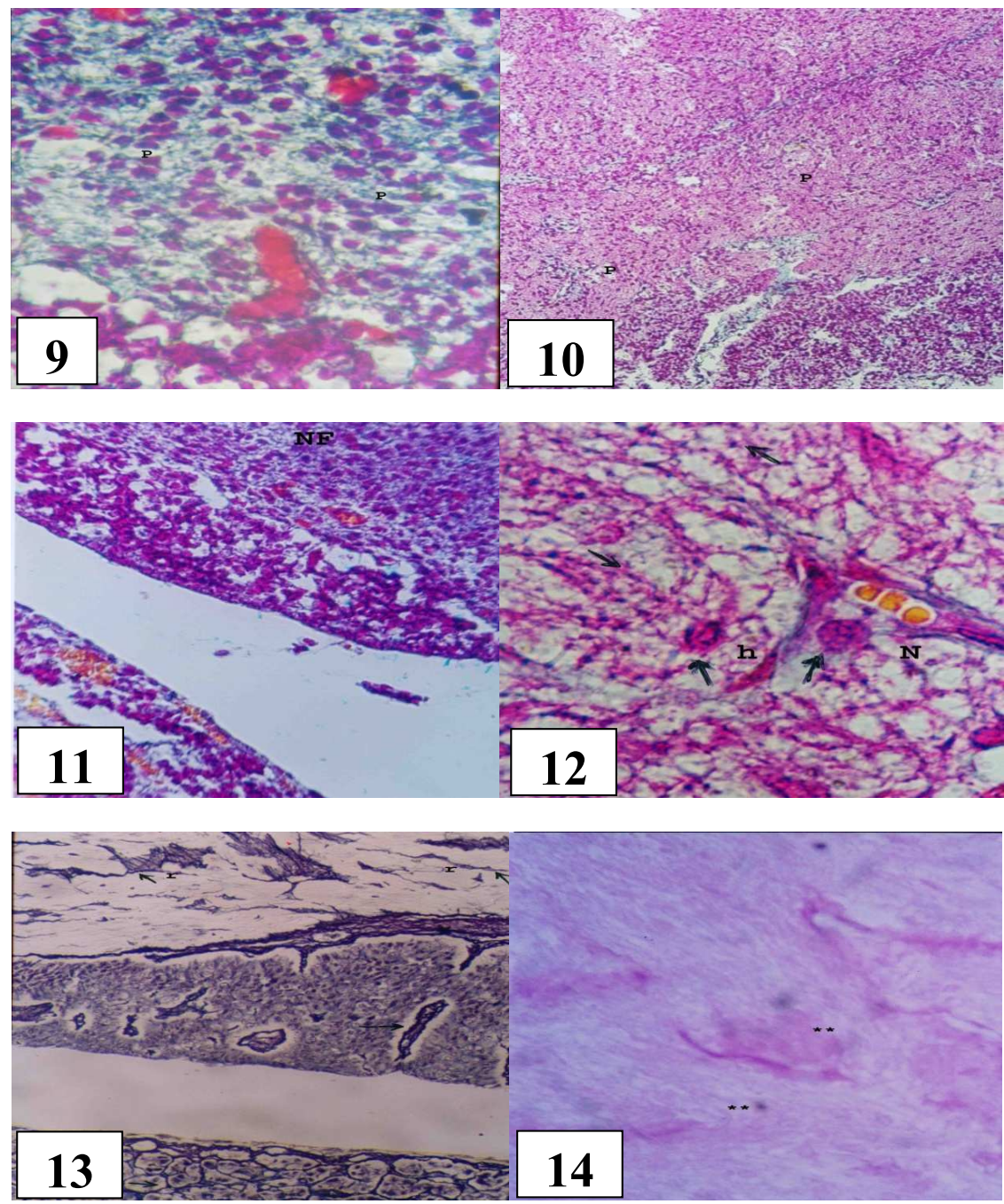

Fig.9: Sagittal section in the pituitary gland of the buffalo fetus at $180 \mathrm{~mm} \mathrm{CVRL}$; showing; the increased size pituicytes (P). BR-AB-OFG X40

Fig.10: Sagittal section in the pituitary gland of the buffalo fetus at $450 \mathrm{~mm} \mathrm{CVRL;} \mathrm{showing;} \mathrm{the} \mathrm{condensed} \mathrm{pi-}$ tuicytes in the center of the gland $(P)$

BR-AB-OFG .X40

Fig.11: Sagittal section in the pituitary gland of the buffalo fetus at $600 \mathrm{~mm}$ CVRL; showing; the increased nerve tracts (NF). BR-AB-OFG X40

Fig.12: Sagittal section in the pituitary gland of the buffalo fetus at $650 \mathrm{~mm} \mathrm{CVRL;} \mathrm{showing;} \mathrm{the} \mathrm{herring} \mathrm{bodies}$ (h) and the neurosecretory materials (N). BR-AB-OFG .X100

Fig.13: Sagittal section in the pituitary gland of the buffalo fetus at $900 \mathrm{~mm} C V R L$; showing; the reticular fibers (r).Gomori reticulin X10

Fig.14: Sagittal section in the pituitary gland of the buffalo fetus at $900 \mathrm{~mm}$ CVRL; showing; moderate PAS positive reaction in the Nerve tracts of the pars nervosa $\left({ }^{* *}\right)$. Alcian blue- PAS combination.X40

J. vet. anat.
Vol 1 No1, (2008) 22 - 28 

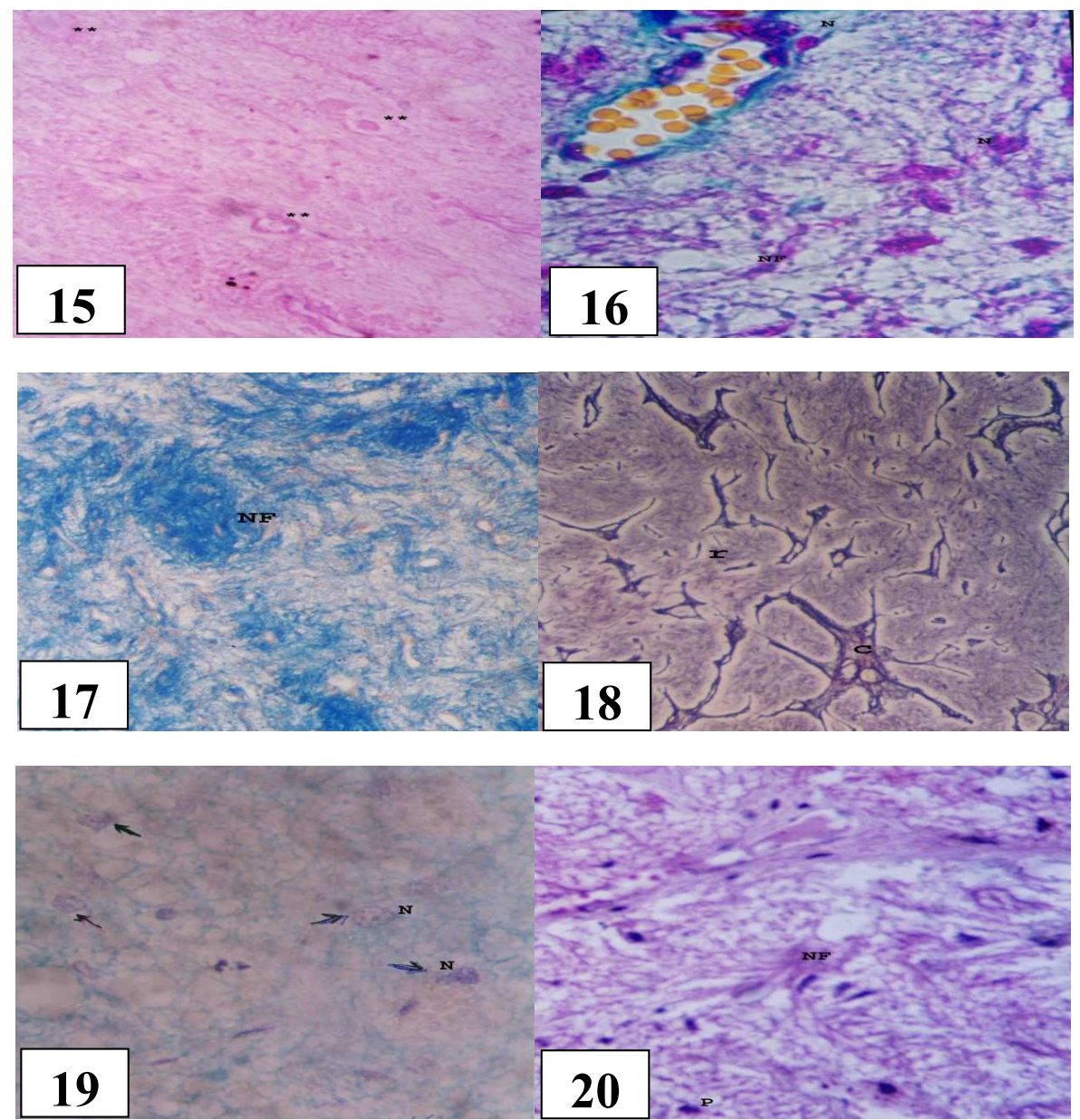

Fig.15: Sagittal section in the pituitary gland of the buffalo fetus at $900 \mathrm{~mm}$ CVRL; showing; weak to moderate PAS positive reaction in the Nerve tracts of the pars nervosa, herring bodies and pituicytes ( $\left.{ }^{* *}\right)$.PAS X40

Fig.16: Sagittal section in the pituitary gland of the buffalo at 1.5 month showing; the neurosecretory bodies $(\mathrm{N})$ and the nerve tracts (NF).BR-AB-OFG X100

Fig.17: Sagittal section in the pituitary gland of the buffalo at 2.5years showing; the nerve tracts orientation (NF).Aldehyde fuchsin aniline blue $\mathrm{X} 100$

Fig.18: Sagittal section in the pituitary gland of the buffalo at 3 years showing; the reticular fibers $(r)$ and the collagen fibers (c). Gomori reticulin X100

Fig.19: Sagittal section in the pituitary gland of the buffalo at 5years showing; the neurosecretory bodies $(\mathrm{N})$.

Per acetic alcian blue X100

Fig.20: Sagittal section in the pituitary gland of the buffalo at 11years showing; the nerve tracts (NF), Pituicytes $(\mathrm{P})$ and the herring bodies $(\mathrm{h})$.

H\&E X10 